\title{
Written pretest information and germline BRCA1/2 pathogenic variant testing in unselected breast cancer patients: predictors of testing uptake
}

\author{
Martin P. Nilsson, MD, $\mathrm{PhD}^{1,2}$, Erik D. Nilsson, $\mathrm{MD}, \mathrm{PhD}^{3}$, Barbro Silfverberg, $\mathrm{BN}^{4}$, Åke Borg, $\mathrm{PhD}^{1}$ and \\ Niklas Loman, MD, PhD ${ }^{1,2}$
}

Purpose: This study aimed to evaluate predictors of testing uptake among unselected breast cancer patients who were offered germline $B R C A 1 / 2$ testing in a prospective study.

Methods: Pretest information was provided by a standardized invitation letter instead of in-person counseling. Data was abstracted from medical records. Using multivariate logistic regressions, predictors of testing uptake were analyzed.

Results: The overall uptake of testing was 67\% (539 of 805 patients). Low uptake rates were found for patients aged $\geq 80$ years (33\%), and patients born outside of Europe (37\%). In adjusted analysis, age $\geq 80$ years (odds ratio [OR] $0.10 ; P=0.002$ ), psychiatric disorders (OR $0.46 ; P=0.006$ ), occupation requiring at least 3 years of university or college education (OR 2.03; $P=$ 0.003 ), and breast cancer or ovarian cancer in first-degree or second-degree relatives (OR 1.66; $P=0.02$ ) were independently associated with uptake of $B R C A 1 / 2$ testing. Somatic comorbidity in patients aged $<70$ years was associated with lower testing uptake.

Conclusion: Testing uptake varies across different subgroups according to patient-related factors that are readily available in the medical records. Knowledge about these factors enables health care professionals to identify patients who are less likely to pursue genetic testing.

Genetics in Medicine (2019) 21:89-96; https://doi.org/10.1038/s41436018-0021-9

Key words: Breast cancer; Genetic testing; Written information; Predictors; Uptake

\section{INTRODUCTION}

Carriers of germline pathogenic variants in BRCA1 and $B R C A 2$ have very high risks of breast cancer and ovarian cancer. ${ }^{1}$ Female carriers who are aware of their pathogenic variant carrier status can opt for prophylactic surgeries or surveillance programs, and thereby, substantially decrease their risk of cancer-related death., ${ }^{2,3}$ Despite the advantages associated with genetic testing, a large proportion of patients who are actively approached and offered genetic testing do not pursue testing. ${ }^{4,5}$ Studies on predictors of genetic testing uptake are needed to identify subgroups of patients that are less likely to be tested. Most previous studies have been retrospective and have focused on cohorts of patients enriched for $B R C A 1 / 2$ pathogenic variant carriers, i.e., highrisk cohorts. These studies have found that young age, high level of education, high income, and a positive family history are independently associated with increased rates of genetic counseling and testing. ${ }^{6-10}$ Ethnic minorities have consistently been shown to have lower rates of testing. ${ }^{11-14}$

Two randomized trials have compared telephone genetic counseling with the standard procedure of in-person counseling, ${ }^{15,16}$ and both of these have now reported on predictors of testing uptake. ${ }^{17,18}$ In the first study, in-person counseling, higher knowledge, lower perceived stress, and nonminority ethnicity were associated with higher testing uptake. Ethnicity moderated the association between randomization group and testing, meaning that minority women were least likely to pursue testing if randomized to the telephone intervention group. ${ }^{17}$ In the second study, inperson counseling, higher perceived comparative pathogenic variant risk, higher cancer distress, a positive family history, and no cost concerns were associated with higher testing uptake. Distress, perceived comparative pathogenic variant risk, and education moderated the association between randomization group and testing. ${ }^{18}$

Compared with in-person or telephone pretest genetic counseling, written information is a further simplification of the testing procedure. In a nonrandomized prospective study (BRCAsearch), we recently showed that written pretest information to unselected breast cancer patients was feasible, and associated with an uptake of germline $B R C A 1 / 2$ testing in $2 / 3$ of the patients. ${ }^{19}$ Here, we report on predictors of genetic testing uptake in the BRCAsearch study.

\footnotetext{
${ }^{1}$ Division of Oncology and Pathology, Department of Clinical Sciences, Lund University, Lund, Sweden; ${ }^{2}$ Department of Hematology, Oncology and Radiation Physics, Skane University Hospital, Lund, Sweden; ${ }^{3}$ Clinical Memory Research Unit, Department of Clinical Sciences Malmö, Lund University, Lund, Sweden; ${ }^{4}$ Department of Clinical Genetics, Laboratory Medicine Region Skåne, Lund, Sweden. Correspondence: Martin P. Nilsson (martin.nilsson@med.lu.se)
} 


\section{MATERIALS AND METHODS}

\section{Study population}

The study population has been described in detail elsewhere. ${ }^{19}$ Briefly, patients diagnosed with nonmetastatic breast cancer at three participating hospitals in south Sweden were prospectively offered analysis of germline pathogenic variants in $B R C A 1$ and $B R C A 2$, unselected for age at diagnosis or family history of cancer (BRCAsearch, ClinicalTrials.gov identifier: NCT02557776). Pretest information was provided by a standardized invitation letter instead of in-person genetic counseling. The invitation letter was given to the patient by the nurse at the regular visit to the surgeon approximately a week after primary surgery, or by the oncologist at the time of information about neoadjuvant chemotherapy. For nonconsenting patients, a reminder was sent by mail at a median time of 4.5 months after the invitation letter. Patients fulfilling any of the following exclusion criteria were not given the invitation letter: (1) the patient is unable to understand the written information in Swedish; (2) the patient is in a psychological state, due to chronic or temporary reasons, where one could suspect that information about the study substantially could be detrimental to their psychological wellbeing.

As previously reported, the invitation letter was given to 818 patients during the time period February 2015-August 2016. ${ }^{19}$ Following confirmation of the pathological anatomical diagnosis in the medical records and pathology reports, it turned out that one patient only had lobular carcinoma in situ, and she was therefore excluded. Twelve patients had not consented to further follow-up, and they were also excluded. The remaining 805 patients constituted the present study population (Fig. 1).

In our health care region, genetic counseling and testing are free of charge for all breast cancer patients. Medical health care copayment is limited to a maximum of 1100 SEK ( 127 USD) per 12 months, including surveillance programs and prophylactic surgeries for all $B R C A 1 / 2$ pathogenic variant carriers. Therefore, economic barriers are unlikely to have contributed to decisions about testing uptake.

\section{Data collection}

The aim of the present study was to analyze predictors of genetic testing uptake, i.e., to study if patient, tumor, or treatment related factors were associated with genetic testing uptake. Before the data collection was initiated, it was determined that the variables listed in Table $\mathbf{1}$ would be collected. First, some tumor and treatment characteristics were collected by cross-referencing with the INCA database, where some data from all breast cancer patients in our health care region are prospectively recorded. Then, the information from the INCA database was supplemented with patient, tumor, and treatment characteristics abstracted from the medical records. In case of discrepancies, the information in the medical records took precedence. Every study participant's medical record was reviewed by an oncologist (MPN). As described in detail elsewhere, ${ }^{19}$ BRCAsearch was a substudy of a biobank research study (SCAN-B, ClinicalTrials.gov identifier: NCT02306096). Therefore, all patients in the present study population $(n=805)$ had allowed their medical data to be accessed.

Either a ductal carcinoma in situ (DCIS) or an invasive breast cancer in the contralateral breast was considered a contralateral breast cancer (CBC). For patients with synchronous bilateral breast cancer, tumor characteristics of the side with the highest tumor stage were recorded. Some patients were offered inclusion in BRCAsearch due to an ipsilateral event following a previous breast cancer. It was not always possible to differentiate a true local recurrence from a new primary tumor, and both were therefore denoted an ipsilateral event. A previous ipsilateral event or a synchronous or metachronous contralateral breast cancer were grouped together as "previous breast cancer."

More than $90 \%$ of the patients who were treated with adjuvant or neoadjuvant chemotherapy received three cycles of epirubicin-cyclophosphamide $\mathrm{q} 3 \mathrm{w}$ followed by three cycles of docetaxel $\mathrm{q} 3 \mathrm{w}$. Postoperative radiation therapy was delivered with either $50 \mathrm{~Gy}$ in 25 fractions or $40 \mathrm{~Gy}$ in 15 fractions, starting 4 weeks after surgery or 4 weeks after the last day of chemotherapy treatment.

Information about occupation was collected from the medical records. For senior citizens, previous occupation was recorded if that information was available in the medical records. Different occupations were categorized into three groups based on the minimum level of education required. Group 1 consisted of occupations requiring little formal education other than compulsory school (e.g., secretary, shop assistant, farmer). Occupations requiring some, but less than 3 years, of vocational school or college education were allocated to group 2 (e.g., assistant nurse, teacher's assistant, dental hygienist). Group 3 consisted of occupations requiring at least 3 years of college or university education, equivalent to a bachelor's degree (e.g., nurse, teacher, librarian) or a master's degree (e.g., physician, professor, civil engineer).

Information about psychiatric disorders was abstracted from the medical records. A psychiatric disorder was defined as a present or past (during the past 10 years) diagnosis of any of the following: minor or major depression, anxiety disorders, bipolar disorder, schizophrenia or other psychotic disorders, posttraumatic stress disorder, and eating disorders. Only two study participants had bipolar disorder and none had schizophrenia; the great majority of psychiatric disorders were depressions and anxiety disorders. There were also 42 patients who were currently treated with psychiatric medications, but with no psychiatric disorder noted in the surgical or oncological medical records; they were allocated to the group psychiatric disorders $=$ Yes. Most of these patients were taking selective serotonin reuptake inhibitors $(n=34)$. The others were taking venlafaxine $(n=2)$, mirtazapine $(n=2)$, clomipramine $(n=1)$, flupentixol $(n=1)$, or daily doses of benzodiazepines $(n=2)$.

Information about somatic comorbidity was abstracted from the medical records, and coded according to the 


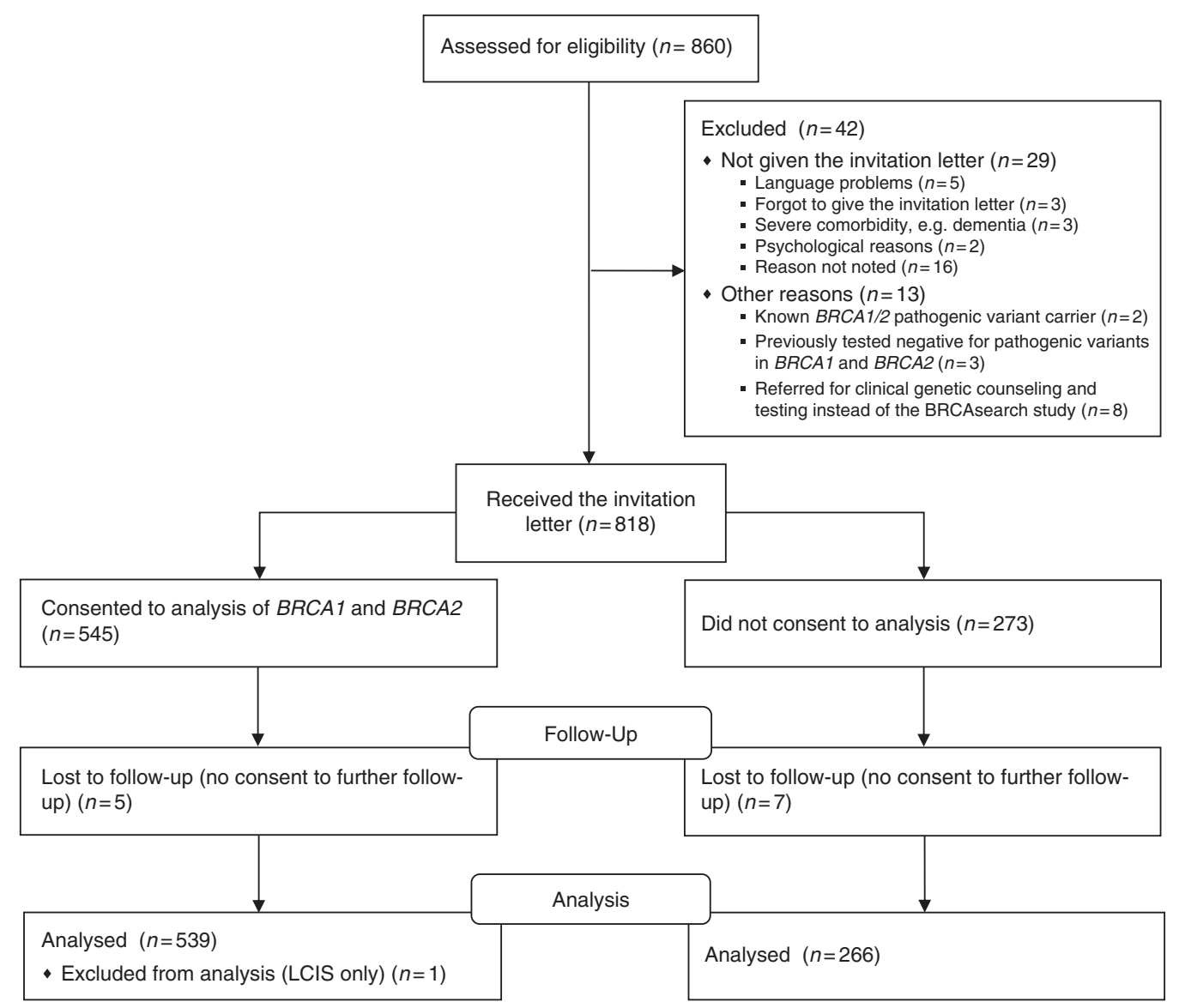

Fig. 1 Flowchart of study enrollment, follow-up, and analysis regarding predictors of uptake of BRCA1/2 testing. LCIS, lobular carcinoma in situ

Charlson comorbidity index $(\mathrm{CCI}) .^{20} \mathrm{~A}$ recent diagnosis of breast cancer rendered 2 points, and accordingly, no patient had a CCI of less than 2. Age categories are usually included in the CCI, but because we aimed to include age as a separate variable in the logistic regression models, we did not include age in the CCI. Therefore, CCI in this paper refers to CCI excluding age.

\section{Statistical analyses}

Differences in patient, tumor, and treatment characteristics between patients who consented to testing and patients who did not consent to testing were assessed using Pearson Chisquare test, independent samples $t$-test, and Mann-Whitney $\mathrm{U}$ test. Unadjusted associations between all variables in Table 1 and testing uptake were evaluated using logistic regression. Age at diagnosis was categorized into age groups to account for nonlinear associations, and to make interpretations of the results easier.

Variable selection for multivariate logistic regression (Enter) in model 1 was based on the results of previous studies. We also included somatic and psychiatric comorbidity in model 1, based on a prespecified hypothesis that these variables might be associated with testing uptake. In model 2 , variables with a significance of $P \leq 0.20$ in unadjusted analyses were entered into the model, and all variables from model 1 were retained.

All analyses were conducted using SPSS version 22.0 (SPSS Inc., Chicago, Illinois, USA). All tests were two-sided. For the results and the discussion, $P$ values below 0.05 were considered statistically significant.

\section{RESULTS}

Patient, tumor, and treatment characteristics are listed in Table 1. Within the present study population, 539 of 805 patients consented to germline pathogenic variant testing of $B R C A 1$ and BRCA2 (Fig. 1). Accordingly, the overall uptake of testing was $67.0 \%$ (539/805). The uptake of testing was remarkably similar across the different study sites in Helsingborg (66.8\%), Kristianstad (66.7\%), and Malmö (67.7\%). Patients who consented to testing were younger compared with patients who did not consent to testing (mean age 61.9 vs. 67.1 years; $P<0.001$ ). In unadjusted analyses, no significant differences were seen between the age categories $<50$ years, 50-59 years, and 60-69 years regarding uptake of testing. In contrast, patients aged 70-79 years (odds ratio $[\mathrm{OR}] 0.54 ; P=0.01$ ) and patients aged $\geq 80$ years (OR $0.17 ; P<0.001)$ were less likely to pursue testing (Table 2). 
Table 1 Patient, tumor, and treatment characteristics

\begin{tabular}{|c|c|c|c|c|}
\hline Variable & 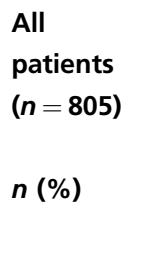 & $\begin{array}{l}\text { Did not } \\
\text { consent to } \\
\text { testing } \\
(n=266) \\
n(\%)\end{array}$ & 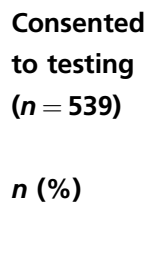 & $\begin{array}{l}P \\
\text { value }^{a}\end{array}$ \\
\hline \multicolumn{5}{|c|}{ Age at diagnosis (years) } \\
\hline Mean; SD & $63.6 ; 12.4$ & $67.1 ; 12.8$ & $61.9 ; 11.8$ & $<0.001^{b}$ \\
\hline $\begin{array}{l}\text { Median; } \\
\text { range }\end{array}$ & $\begin{array}{l}65.4 \\
26.2-94.3\end{array}$ & $\begin{array}{l}68.7 ; \\
35.7-91.6\end{array}$ & $\begin{array}{l}64.0 \\
26.2-94.3\end{array}$ & $<0.001^{c}$ \\
\hline $\begin{array}{l}\text { Age at } \\
\text { diagnosis, } \\
\text { categories }\end{array}$ & & & & $<0.001$ \\
\hline$<50$ years & $137(17.0)$ & $34(12.8)$ & $103(19.1)$ & \\
\hline $50-59$ years & $147(18.3)$ & $38(14.3)$ & $109(20.2)$ & \\
\hline $60-69$ years & $261(32.4)$ & $76(28.6)$ & $185(34.3)$ & \\
\hline 70-79 years & $194(24.1)$ & $74(27.8)$ & $120(22.3)$ & \\
\hline$\geq 80$ years & $66(8.2)$ & $44(16.5)$ & $22(4.1)$ & \\
\hline $\begin{array}{l}\text { Occupation, } \\
\text { categories }^{d}\end{array}$ & & & & $<0.001$ \\
\hline 1 & $300(37.3)$ & $114(56.7)$ & $186(40.3)$ & \\
\hline 2 & $170(21.1)$ & $44(21.9)$ & $126(27.3)$ & \\
\hline 3 & $192(23.9)$ & $43(21.4)$ & $149(32.3)$ & \\
\hline Missing & $143(17.8)$ & & & \\
\hline Children & & & & 0.73 \\
\hline No & $99(12.3)$ & $34(13.0)$ & $65(12.1)$ & \\
\hline Yes & $697(86.6)$ & $227(87.0)$ & $470(87.9)$ & \\
\hline Missing & $9(1.1)$ & & & \\
\hline Previous $\mathrm{BC}^{\mathrm{e}}$ & & & & 0.13 \\
\hline No & $695(86.3)$ & $223(83.8)$ & $472(87.7)$ & \\
\hline Yes & $109(13.5)$ & $43(16.2)$ & $66(12.3)$ & \\
\hline Missing & $1(0.1)$ & & & \\
\hline $\begin{array}{l}B C \text { or } O C \text { in } \\
\text { FDR or SDR }\end{array}$ & & & & 0.05 \\
\hline No & $517(64.2)$ & $176(73.9)$ & $341(66.9)$ & \\
\hline Yes & $231(28.7)$ & $62(26.1)$ & $169(33.1)$ & \\
\hline Missing & $57(7.1)$ & & & \\
\hline $\begin{array}{l}\text { Psychiatric } \\
\text { disorder }\end{array}$ & & & & 0.002 \\
\hline No & 709 (88.1) & $221(83.1)$ & $488(90.7)$ & \\
\hline Yes & 95 (11.8) & 45 (16.9) & $50(9.3)$ & \\
\hline Missing & $1(0.1)$ & & & \\
\hline $\begin{array}{l}\text { Charlson } \\
\text { comorbidity } \\
\text { index (CCI) }\end{array}$ & & & & $<0.001$ \\
\hline $\mathrm{CCl}=2$ & $634(78.8)$ & $186(69.9)$ & $448(83.3)$ & \\
\hline $\mathrm{CCl} \geq 3$ & $170(21.1)$ & $80(30.1)$ & $90(16.7)$ & \\
\hline Missing & $1(0.1)$ & & & \\
\hline County of birth & & & & 0.18 \\
\hline $\begin{array}{l}\text { Outside of } \\
\text { Sweden }\end{array}$ & $75(9.3)$ & $30(11.3)$ & $45(8.3)$ & \\
\hline Sweden & $730(90.7)$ & $236(88.7)$ & $494(91.7)$ & \\
\hline Invasiveness & & & & 0.20 \\
\hline
\end{tabular}

Table 1 continued

\begin{tabular}{|c|c|c|c|c|}
\hline Variable & 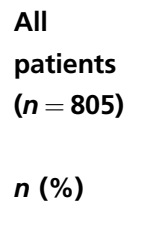 & $\begin{array}{l}\text { Did not } \\
\text { consent to } \\
\text { testing } \\
(n=266) \\
n(\%)\end{array}$ & 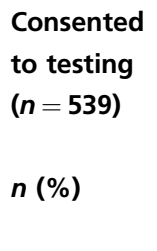 & $\begin{array}{l}P \\
\text { value }^{a}\end{array}$ \\
\hline Only DCIS & $59(7.3)$ & $24(9.0)$ & $35(6.5)$ & \\
\hline $\begin{array}{l}\text { Invasive } \\
\text { cancer }\end{array}$ & $746(92.7)$ & $242(91.0)$ & $504(93.5)$ & \\
\hline $\begin{array}{l}\text { Lymph node } \\
\text { status }\end{array}$ & & & & 0.08 \\
\hline Negative & $544(67.6)$ & $191(72.3)$ & $353(66.1)$ & \\
\hline Positive & $254(31.6)$ & $73(27.7)$ & 181 (33.9) & \\
\hline Missing & $7(0.9)$ & & & \\
\hline Surgery & & & & 0.02 \\
\hline $\begin{array}{c}\text { Breast- } \\
\text { conserving }\end{array}$ & $518(64.3)$ & $156(58.9)$ & $362(67.7)$ & \\
\hline Mastectomy & $280(34.8)$ & $108(40.8)$ & $172(32.1)$ & \\
\hline $\begin{array}{l}\text { No surgery } \\
\text { or missing }\end{array}$ & $7(0.9)$ & & & \\
\hline $\begin{array}{l}\text { (Neo)adjuvant } \\
\text { chemotherapy }^{f}\end{array}$ & & & & 0.01 \\
\hline No & $509(63.2)$ & $185(69.5)$ & $324(60.1)$ & \\
\hline Yes & $296(36.8)$ & $81(30.5)$ & 215 (39.9) & \\
\hline $\begin{array}{l}\text { Adjuvant } \\
\text { endocrine } \\
\text { treatment }\end{array}$ & & & & 0.03 \\
\hline No & $278(34.5)$ & $106(39.8)$ & 172 (31.9) & \\
\hline Yes & $527(65.5)$ & $160(60.2)$ & $367(68.1)$ & \\
\hline Radiotherapy & & & & $<0.001$ \\
\hline No & $176(21.9)$ & $79(29.7)$ & $97(18.0)$ & \\
\hline Yes & $629(78.1)$ & $187(70.3)$ & $442(82.0)$ & \\
\hline $\begin{array}{l}\text { Study site, } \\
\text { hospital }\end{array}$ & & & & 0.97 \\
\hline Helsingborg & $328(40.7)$ & $109(41.0)$ & $219(40.6)$ & \\
\hline Kristianstad & $279(34.7)$ & $93(35.0)$ & $186(34.5)$ & \\
\hline Malmö & $198(24.6)$ & $64(24.1)$ & $134(24.9)$ & \\
\hline
\end{tabular}

apearson Chi-square for all if otherwise not noted

${ }^{b}$ Independent samples $t$-test

"Mann-Whitney $U$ test

${ }^{\mathrm{d}}$ See Materials and Methods section for definitions of categories

eprevious breast cancer (invasive or DCIS) in the ipsilateral or in the contralateral breast

${ }^{f}$ Neoadjuvant or adjuvant chemotherapy

$S D$ standard deviation, $D C I S$ ductal carcinoma in situ, $B C$ breast cancer, $O C$ ovarian cancer, FDR first-degree relative, $S D R$ second-degree relative

\section{Main results of adjusted analyses}

In model 1, we adjusted for patient-related variables (Table 2). Entering also tumor and treatment characteristics into the model (model 2) had only a marginal effect on the odds ratios and corresponding $P$ values of the patient-related variables. In the fully adjusted logistic regression model, age $\geq 80$ years (OR $0.10 ; P=0.002)$, occupation requiring at least 3 years of university or college education (OR 2.03; $P=0.003$ ), breast cancer or ovarian cancer in first-degree or second-degree 
Table 2 Logistic regression models assessing predictors of uptake of $B R C A 1 / 2$ testing

\begin{tabular}{|c|c|c|c|c|c|c|c|c|c|}
\hline \multirow[b]{2}{*}{ Variable } & \multirow[b]{2}{*}{ Crude OR } & \multirow[b]{2}{*}{$95 \% \mathrm{Cl}$} & \multirow[b]{2}{*}{$P$ value } & \multicolumn{3}{|c|}{$\begin{array}{l}\text { Model 1: } \\
\text { Patient factors }\end{array}$} & \multicolumn{3}{|c|}{$\begin{array}{l}\text { Model 2: } \\
\text { Patient, tumor, and treatment factors }\end{array}$} \\
\hline & & & & OR & $95 \% \mathrm{Cl}$ & $P$ value & OR & $95 \% \mathrm{Cl}$ & $P$ value \\
\hline$<50$ years & ref. & & & ref. & & & ref. & & \\
\hline $50-59$ years & 0.95 & $0.55-1.62$ & 0.84 & 1.00 & $0.56-1.78$ & 1.00 & 1.07 & $0.60-1.93$ & 0.81 \\
\hline $60-69$ years & 0.80 & $0.50-1.29$ & 0.36 & 0.84 & $0.50-1.42$ & 0.52 & 0.94 & $0.55-1.63$ & 0.84 \\
\hline$\geq 80$ years & 0.17 & $0.09-0.31$ & $<0.001$ & 0.08 & $0.02-0.30$ & $<0.001$ & 0.10 & $0.03-0.44$ & 0.002 \\
\hline \multicolumn{10}{|l|}{ Occupation, categories } \\
\hline 1 & ref. & & & ref. & & & ref. & & \\
\hline 2 & 1.76 & $1.16-2.66$ & 0.01 & 1.35 & $0.86-2.12$ & 0.19 & 1.43 & $0.91-2.25$ & 0.13 \\
\hline 3 & 2.12 & $1.41-3.21$ & $<0.001$ & 1.97 & $1.24-3.12$ & 0.004 & 2.03 & $1.26-3.26$ & 0.003 \\
\hline \multicolumn{10}{|l|}{$\mathrm{BC}$ or $\mathrm{OC}$ in FDR or SDR } \\
\hline Yes vs. no & 1.41 & $1.00-1.98$ & 0.05 & 1.71 & $1.12-2.61$ & 0.01 & 1.66 & $1.08-2.55$ & 0.02 \\
\hline \multicolumn{10}{|l|}{ Psychiatric disease } \\
\hline Yes vs. no & 0.50 & $0.33-0.78$ & 0.002 & 0.48 & $0.28-0.82$ & 0.007 & 0.46 & $0.27-0.80$ & 0.006 \\
\hline \multicolumn{10}{|l|}{$\mathrm{CCl}$} \\
\hline$\geq 3$ vs. 2 & 0.47 & $0.33-0.66$ & $<0.001$ & 0.63 & $0.40-1.01$ & 0.06 & 0.69 & $0.42-1.12$ & 0.13 \\
\hline \multicolumn{10}{|l|}{ Country of birth } \\
\hline Outside of Sweden vs. Sweden & 0.72 & $0.44-1.17$ & 0.18 & 0.58 & $0.33-1.03$ & 0.06 & 0.58 & $0.32-1.04$ & 0.07 \\
\hline \multicolumn{10}{|l|}{ Invasiveness } \\
\hline DCIS vs. invasive cancer & 0.70 & $0.41-1.20$ & 0.20 & & & & 1.31 & $0.62-2.78$ & 0.48 \\
\hline \multicolumn{10}{|l|}{ Adjuvant endocrine treatment } \\
\hline Yes vs. no & 1.41 & $1.04-1.92$ & 0.03 & & & & 1.34 & $0.88-2.03$ & 0.18 \\
\hline \multicolumn{10}{|l|}{ Radiotherapy } \\
\hline Yes vs. no & 1.93 & $1.37-2.71$ & $<0.001$ & & & & 1.75 & $0.85-3.60$ & 0.13 \\
\hline
\end{tabular}

relatives (OR 1.66; $P=0.02)$, and psychiatric disorders (OR $0.46 ; P=0.006)$ were independently associated with uptake of $B R C A 1 / 2$ testing.

\section{Country of birth}

Seventy-five patients (9.1\% of the study population) were born outside of Sweden. After adjustments, a trend for a lower uptake of testing was seen for them compared with patients born in Sweden (OR 0.58; $P=0.07$ ). In an exploratory analysis, the group born outside of Sweden was subdivided into (1) born in the Nordic countries, (2) born in non-Nordic European countries, and (3) born outside of Europe. Due to small numbers, no multivariate analyses were carried out for these subgroups. Despite a relatively young age at diagnosis (mean 52.4 years), a very low uptake rate was noted for patients born outside of Europe (7 of $19=37 \%$ ).

\section{Somatic comorbidity}

One hundred seventy patients ( $21.1 \%$ of the study population) had at least one extra point on the CCI scoring in addition to the two points implicated by the breast cancer diagnosis, i.e., CCI $\geq 3$. In unadjusted analysis, these patients had a significantly lower uptake of testing (CCI $\geq 3$ vs. $\mathrm{CCI}=2$, OR $0.47 ; P<0.001)$, but the results were attenuated after adjustments (model 1: OR 0.63; $P=0.06$, model 2: OR 0.69; $P$ $=0.13$ ). As expected, CCI $\geq 3$ was less common among 
patients aged $<70$ years ( 85 of $545=15.6 \%)$ compared with patients aged $\geq 70$ years $(85$ of $259=32.7 \%$ ). The uptake of testing was significantly lower for patients with somatic comorbidity, i.e., $\mathrm{CCI} \geq 3$, among patients aged $<70$ years $(56.5$ vs. $75.9 \%$; $P<0.001)$, which was not the case for patients aged $\geq 70$ years ( 49.4 vs. $56.9 \% ; P=0.26$ ). Restricting the adjusted analyses to patients aged $<70$ years in an exploratory analysis, CCI $\geq 3$ was associated with a lower uptake of testing (model 1: OR 0.56; $P=0.03$, model 2: OR 0.60; $P=0.08$ ).

\section{Neoadjuvant vs. adjuvant chemotherapy}

In Table 1 and Table 2, (neo)adjuvant chemotherapy refers to either neoadjuvant or adjuvant chemotherapy. In unadjusted analysis, (neo)adjuvant chemotherapy was associated with a higher uptake of testing (OR $1.51 ; P=0.01$ ). After adjustments, no association was seen (OR $1.12 ; P=0.62$ ). In a post hoc analysis, we hypothesized that differences in the setting in which the invitation letter was delivered might influence uptake rates. Patients who were treated with adjuvant chemotherapy $(n=238)$ were given the invitation letter by the nurse at the Department of Surgery, prior to being referred to the Department of Oncology. In contrast, most of the patients who were treated with neoadjuvant chemotherapy $(n=58)$ were given the invitation letter by their medical oncologist. Patients treated with neoadjuvant chemotherapy were younger at diagnosis compared with patients treated with adjuvant chemotherapy (mean 53.0 vs. 58.9 years; $P=$ 0.001). The uptake of testing was higher for patients treated with neoadjuvant $(86.2 \%)$ compared with patients treated with adjuvant chemotherapy (69.3\%), even after adjustment for age at diagnosis ( $\mathrm{OR} 2.39 ; P=0.04$ ). Adjusting for all patient-related variables in model 1 , the odds ratio for neoadjuvant vs. adjuvant chemotherapy with uptake of testing as dependent variable was $2.15(P=0.09)$. Among patients treated with neoadjuvant chemotherapy, 13 had triplenegative breast cancer (TNBC) and 45 had non-TNBC; the uptake of testing was similar for TNBC (11 of 13) and nonTNBC (39 of 45). Accordingly, the higher testing uptake in the neoadjuvant subgroup could not be explained by increased uptake rates among TNBC patients.

\section{Predictors of uptake following the reminder}

Of 539 patients consenting to testing, 84 (15.6\%) consented following a reminder. The mean age at diagnosis was similar for patients who consented following a reminder compared with patients who consented without a reminder (63.2 vs. 61.6 years; $P=0.26$ ). An exploratory analysis was undertaken to investigate if any characteristics were associated with an uptake following a reminder compared with an uptake without a reminder. The proportion of all consenting patients who consented following a reminder was between 12 and 19\% within all subgroups listed in Table 1 , and no $P$ values were $<0.05$ (data not shown). Accordingly, a reminder increased uptake rates in all subgroups of patients, but we were not able to identify any subgroup of patients who would be in more need of a reminder than others.

\section{DISCUSSION}

Our present paper is the first to report on patient characteristics of importance for genetic testing uptake when unselected breast cancer patients are offered germline BRCA1/ 2 testing through a simplified testing protocol. In the near future, simplified testing protocols offered to a majority ofor even to all-breast cancer patients are likely to replace the hitherto used standard procedure. Therefore, we hope that the results of our study will be useful for other researchers and clinicians. The overall testing uptake in our study was $67 \%$. For two subgroups, very low uptake rates were noted: patients aged $\geq 80$ years $(33 \%)$, and patients born outside of Europe (37\%).

The results of our prospective study confirmed a number of findings from previous studies, mainly carried out in cohorts enriched for BRCA1/2 pathogenic variant carriers. ${ }^{6-10}$ High age and occupations requiring a low level of education were independently associated with lower testing uptake. Family history of breast or ovarian cancer-but not personal history of breast cancer-was associated with higher testing uptake.

In contrast to most other studies, we extracted data from the medical records. The rigorous and time-consuming data collection method enabled us to acquire detailed and valid data on psychiatric and somatic comorbidity. To the best of our knowledge, comorbidity has not been evaluated in relation to uptake of $B R C A 1 / 2$ testing previously. Some other studies have collected data on distress from self-reported questionnaires, and have found conflicting results regarding the association between levels of distress and testing uptake. ${ }^{17,18,21}$ However, "cancer distress" or "perceived stress" is not synonymous to psychiatric disorders. Our finding that persons with psychiatric disorders had a significantly lower uptake of testing is therefore novel and most likely clinically relevant. Of note, the nonrandomized study design precludes any comparisons with the standard procedure of in-person genetic counselling. Using data from one of the randomized trials on telephone genetic counseling, Steffen et al. recently showed that cancer distress moderated the effect of counseling and testing; patients with high levels of precounseling cancer distress had a higher uptake of testing in the in-person counseling group, but not in the telephone counseling group. ${ }^{18}$ The method used for pretest information in our study is a further simplification compared with telephone counseling. Whether persons with psychiatric disorders have lower testing uptake irrespective of what pretest information/ counseling method is used, or if they only have a lower testing uptake when simplified methods are used, is a question that merits further research.

In the entire study population, somatic comorbidity was associated with lower testing uptake in unadjusted analysis, but not in the fully adjusted model. To grade and categorize comorbidity, we used the Charlson comorbidity index, which is the most commonly used comorbidity index in research. ${ }^{20}$ It was originally developed to predict one-year mortality, but has since been used for many different types of endpoints, for instance to assess correlations between comorbidity and 
quality of life in breast cancer survivors. ${ }^{22}$ To some extent, somatic comorbidity is a surrogate marker of higher "biological age," which might be an explanation of our exploratory finding that comorbid patients had lower testing uptake in the age group $<70$ years.

At the time of the study, the chemotherapeutic regimens used for neoadjuvant and adjuvant treatment were identical in our health care region. Furthermore, both patients who were scheduled for neoadjuvant and for adjuvant chemotherapy received the invitation letter shortly before commencing chemotherapy treatment. Despite these similarities, the uptake of testing was considerably higher in the neoadjuvant (86.2\%) than in the adjuvant (69.3\%) group, even adjusted for age. The difference in testing uptake between the groups could be a chance finding, but might also be attributed to small, but important, differences between the settings in which the invitation letters were delivered. For instance, most of the patients who were treated with neoadjuvant chemotherapy received the invitation letter from an oncologist, in contrast to the other patients who received the invitation letter from a nurse. Generally, uptake rates have varied enormously between studies. In some, uptake rates have been close to $20 \%$, whereas in others, uptake rates have been $80-90 \%$. $^{15,16,23}$ These differences in uptake rates are most likely not merely a reflection of different study populations, but also of variations in the settings surrounding the testing procedures.

In the present study, 66 patients aged $\geq 80$ years were offered testing, but only 22 of them pursued testing, none of whom turned out to be a pathogenic variant carrier. Given the low uptake rate and low likelihood of identifying pathogenic variants, one could argue that unselected breast cancer patients aged $\geq 80$ years should not be offered germline $B R C A 1 / 2$ pathogenic variant testing. However, BRCA1/2 pathogenic variants are not absent among old breast cancer patients. In a previous publication from our research group, $B R C A 1 / 2$ pathogenic variant analysis was undertaken in a cohort of unselected breast cancer patients. Of 20 identified germline $B R C A 1 / 2$ pathogenic variant carriers in that study, 2 were aged $\geq 80$ years. ${ }^{24}$

In addition to the nonrandomized study design discussed above, there are other limitations to our study. First, the data collection method used did not enable us to collect some variables of potential importance. For instance, level of education was extrapolated from data on occupation, but we had no information about actual education or about knowledge of hereditary cancer and genetic testing, which could have contextualized our findings further. Second, despite including $>800$ patients in the entire study population, the study was not powered to carry out explorative multivariate analyses in some small, but potentially important, subgroups, e.g., patients born outside of Europe. Third, we did not collect data on patientreported reasons for not consenting to genetic testing. A very limited number of studies have investigated patient-reported reasons for not accepting an offer to undergo germline testing of BRCA $1 / 2$ pathogenic variants. ${ }^{5,25,26}$ In a study from Canada, Godard et al. examined why individuals withdrew from genetic testing for breast and ovarian cancer susceptibility. The most commonly given reason was "afraid of the psychological effects of genetic testing" (36.3\%). The second most common reason was "logistic problems such as limited ability to travel, lack of time, personal issues, advanced age, or health problems" $(21.7 \%)$, and the third was "did not see any advantage in being tested" $(14.5 \%)^{26}$

In summary, uptake of $B R C A 1 / 2$ testing varies across different subgroups according to patient-related factors that are readily available in the medical records. Knowledge about these factors enables health care professionals to identify patients who are less likely to pursue genetic testing. As the evidence for a treatment predictive value of $B R C A 1 / 2$ pathogenic variants in breast cancer is increasing, future trials should focus both on ways to increase overall uptake rates, and ways to increase uptake rates in underserved groups.

\section{DECLARATIONS}

The BRCAsearch study was approved by the Regional Ethical Review Board in Lund (Dnr 2009/659, Dnr 2014/681). Informed consent was obtained from all patients in the study population.

\section{ACKNOWLEDGEMENTS}

We are grateful to the patients for participation in the BRCAsearch study, and thank the nurses and surgeons of the Breast Cancer Surgery Units in Helsingborg, Kristianstad, and Malmö for patient recruitment. The work was funded by grants from Skåne County Council's Research and Development Foundation, BioCARE, Mrs. Berta Kamprad Foundation, the Gunnar Nilsson Cancer Foundation, and the Swedish Cancer Society.

\section{DISCLOSURE}

The authors declare no conflicts of interest.

\section{REFERENCES}

1. Kuchenbaecker KB, Hopper JL, Barnes DR, et al. Risks of breast, ovarian, and contralateral breast cancer for BRCA1 and BRCA2 pathogenic variant carriers. JAMA. 2017;317:2402-16.

2. Hartmann LC, Lindor NM. Risk-reducing surgery in hereditary breast and ovarian cancer. N Engl J Med. 2016;374:2404.

3. Kurian AW, Sigal BM, Plevritis SK. Survival analysis of cancer risk reduction strategies for BRCA1/2 pathogenic variant carriers. J Clin Oncol. 2010;28:222-31.

4. Hoberg-Vetti $H$, Bjorvatn $C$, Fiane BE, et al. BRCA1/2 testing in newly diagnosed breast and ovarian cancer patients without prior genetic counselling: the DNA-BONus study. Eur J Hum Genet. 2016;24:881-8.

5. Schlich-Bakker KJ, ten Kroode HF, Warlam-Rodenhuis CC, van den Bout J, Ausems MG. Barriers to participating in genetic counseling and BRCA testing during primary treatment for breast cancer. Genet Med. 2007;9:766-77

6. Ayme A, Viassolo V, Rapiti $E$, et al. Determinants of genetic counseling uptake and its impact on breast cancer outcome: a population-based study. Breast Cancer Res Treat. 2014;144:379-89.

7. Cragun D, Bonner D, Kim J, et al. Factors associated with genetic counseling and BRCA testing in a population-based sample of young Black women with breast cancer. Breast Cancer Res Treat. 2015;151:169-76. 
8. Febbraro T, Robison K, Wilbur JS, et al. Adherence patterns to National Comprehensive Cancer Network (NCCN) guidelines for referral to cancer genetic professionals. Gynecol Oncol. 2015;138:109-14.

9. Hafertepen L, Pastorino A, Morman N, et al. Barriers to genetic testing in newly diagnosed breast cancer patients: do surgeons limit testing? Am J Surg. 2017;214:105-10

10. Vig HS, McCarthy AM, Liao K, Demeter MB, Fredericks T, Armstrong K. Age at diagnosis may trump family history in driving BRCA testing in a population of breast cancer patients. Cancer Epidemiol Biomarkers Prev. 2013;22:1778-85

11. Levy $D E$, Byfield $S D$, Comstock $C B$, et al. Underutilization of BRCA1/2 testing to guide breast cancer treatment: black and Hispanic women particularly at risk. Genet Med. 2011;13:349-55.

12. McCarthy AM, Bristol M, Domchek SM, et al. Health care segregation, physician recommendation, and racial disparities in BRCA1/2 testing among women with breast cancer. J Clin Oncol. 2016;34:2610-8.

13. Meyer LA, Anderson ME, Lacour RA, et al. Evaluating women with ovarian cancer for BRCA1 and BRCA2 pathogenic variants: missed opportunities. Obstet Gynecol. 2010;115:945-52.

14. Susswein LR, Skrzynia C, Lange LA, Booker JK, Graham ML 3rd, Evans JP. Increased uptake of BRCA1/2 genetic testing among African American women with a recent diagnosis of breast cancer. I Clin Oncol. 2008:26:32-36.

15. Kinney AY, Steffen LE, Brumbach BH, et al. Randomized noninferiority trial of telephone delivery of BRCA1/2 genetic counseling compared with in-person counseling: 1-year follow-up. I Clin Oncol. 2016;34:2914-24

16. Schwartz MD, Valdimarsdottir HB, Peshkin BN, et al. Randomized noninferiority trial of telephone versus in-person genetic counseling for hereditary breast and ovarian cancer. J Clin Oncol. 2014;32:618-26.

17. Butrick M, Kelly S, Peshkin BN, et al. Disparities in uptake of BRCA1/2 genetic testing in a randomized trial of telephone counseling. Genet Med. 2015;17:467-75.
18. Steffen LE, Du R, Gammon A, et al. Genetic testing in a population-based sample of breast and ovarian cancer survivors from the REACH randomized trial: cost barriers and moderators of counseling mode. Cancer Epidemiol Biomarkers Prev. 2017;26:1772-80.

19. Nilsson MP, Torngren T, Henriksson K, et al. BRCAsearch: written pretest information and BRCA1/2 germline pathogenic variant testing in unselected patients with newly diagnosed breast cancer. Breast Cancer Res Treat. 2018:168:117-26.

20. Charlson ME, Pompei P, Ales KL, MacKenzie CR. A new method of classifying prognostic comorbidity in longitudinal studies: development and validation. J Chronic Dis. 1987:40:373-83.

21. Sweeny K, Ghane A, Legg AM, Huynh HP, Andrews SE. Predictors of genetic testing decisions: a systematic review and critique of the literature. J Genet Couns. 2014;23:263-88

22. Fu MR, Axelrod D, Guth AA, et al. Comorbidities and quality of life among breast cancer survivors: a prospective study. J Pers Med. 2015:5:229-42.

23. Ropka ME, Wenzel J, Phillips EK, Siadaty M, Philbrick JT. Uptake rates for breast cancer genetic testing: a systematic review. Cancer Epidemiol Biomarkers Prev. 2006;15:840-55.

24. Winter C, Nilsson MP, Olsson E, et al. Targeted sequencing of BRCA1 and BRCA2 across a large unselected breast cancer cohort suggests that one-third of pathogenic variants are somatic. Ann Oncol. 2016;27: $1532-8$.

25. Foster C, Evans DG, Eeles $R$, et al. Non-uptake of predictive genetic testing for BRCA1/2 among relatives of known carriers: attributes, cancer worry, and barriers to testing in a multicenter clinical cohort. Genet Test. 2004;8:23-29.

26. Godard B, Pratte A, Dumont M, Simard-Lebrun A, Simard J. Factors associated with an individual's decision to withdraw from genetic testing for breast and ovarian cancer susceptibility: implications for counseling. Genet Test. 2007;11:45-54. 